\title{
Developments in Indian Energy Sector: Problems and Prospects
}

\author{
Vineet Tiwari ${ }^{1}$, M.Kapshe ${ }^{2}$, A.Deshpande ${ }^{3}$, V.K. Khare ${ }^{4}$, \\ ${ }^{I}$ (Department of Management Studies, MANIT, Bhopal, India) \\ ${ }^{2}$ (Department of Planning, SPA, Bhopal, India) \\ ${ }^{3}$ (Department of Management Studies, NITTTR, Bhopal, India) \\ ${ }^{4}$ (Department of Mechanical Engineering, MANIT, Bhopal, India)
}

\begin{abstract}
India is developing at nearly 8\% economic growth. Several development initiatives have been taken by the Government of India (GOI) to sustain this economic growth. Continued development requires strong energy infrastructure to support this economic transformation in order to remain competitive. To meet the increasing energy demand, many projects have been planned and offered but could not be successfully implemented either on account of deficient legislative and regulatory structure or lack of coordination among execution agencies. It is observed that legislative and institutional frameworks are required to be in sync to facilitate the development process. This paper reviews the major problems faced by Indian energy sector, presents an analytical view of the future prospects and suggests possible measures that can help in improving the situation.
\end{abstract}

Keywords - Energy, development, legislations, institutions,

\section{INTRODUCTION}

With rapidly changing socio-economic structure of the society, energy needs have increased significantly and the supply side is coming under pressure. This has raised the concern to economize on every aspect of energy sector value chain so as to meet the increasing demand in most efficient way. To address this concern, strong policy level initiatives and implementation strategies needs to be drafted and designed. Gaps need to be identified and addressed at planning level with well thought out execution mechanisms. Post liberalization, India has emerged as an economic powerhouse and is poised to grow at about $8 \%$ per annum over the next decade. It is likely that at present growth rates, India will be one of the top three economies of the world by 2030 along with the USA and China.

To sustain economic growth of such proportions, concomitant growth in the infrastructure especially in the electricity sector is of paramount importance along with policy, legislative and administrative initiatives in almost across all the energy sector functionaries. Electricity constitutes a critical input to all major economic activities. It is evident that with continued peak demand deficit of $12-13 \%$ and energy shortage of $6-8 \%$, India would not be able to achieve high levels of economic growth. 'Electricity for all' is not only an economic imperative but also a social obligation. If India is to fulfill its dream of becoming an economic super-power, then the electricity sector has to play a central role in enabling this transformation.

This is well recognized that to ensure growth in the electricity sector it is necessary to invite private sector participation. This will increase competition, breaking the monopoly and leading to development of true market dynamics. Therefore, Government of India (GOI) has been taking path-breaking initiatives on the policy, regulatory and the reforms front. Enactment of the Electricity Act, 2003 was an excellent first step towards creating an efficient and competitive electricity market. Several policy initiatives have been introduced, which have created an enabling framework for private sector participation.

A critical element of the structural reform process, which is currently underway, is the movement towards independent market mechanisms. These market mechanisms are expected to introduce economic efficiencies into the system, create a level playing field for all players and introduce competition across all segments of the business. It is envisaged that the consumers at all levels in the value chain shall benefit from introduction of competition and provision of choice.

The above mentioned reforms can only be achieved by having systematic legislative and institutional approach for the development of India's energy sector. In the $21^{\text {st }}$ century, energy supply and consumption, food crises and climate change are among the issues of major concern to the international arena. Remarkable growth has been registered in the energy sector after independence. It has made significant contributions to the national economy, social welfare and the basic energy needs of the Country. However, today energy sector world across is confronting a number of obstacles in energy reserves, population numbers, domestic and global environmental issues. It is also constrained by industrial and economic structures, financial resources, technologies, management systems, and consumers' culture of energy wastage. 
In 2006, the integrated energy policy was published by GOI. This policy outlines the long-term national energy strategy, touching almost every important issue like conservation, relying on domestic resources, encouraging diverse patterns of development, contribution of science and technology, protecting the environment and increasing international cooperation for mutual benefit. The aim is to build a stable, economical, clean and safe energy supply system, one that will support sustained economic and social development with sustained energy development.

A major prerequisite of the national energy strategy is having in place the relevant legislation, policies, plans, standards, institutions, along with other relevant measures. This is because human behaviors and socioeconomic relations that facilitate energy production, sale, and consumption need to be adjusted and regulated using legal tools. Government energy institutions are charged with the task of implementing national energy strategies, laws, policies, plans and other management measures.

This paper proposes to develop full-fledged understanding about the India's energy sector, identify possible bottlenecks and way forward to improvisation. First, it discusses the existing legislations including laws, regulations and policies. Subsequently the existing structure of energy sector is discussed. In the last section common issues and challenges are highlighted and actions for future development are presented. Lastly paper summarizes the entire discussion to bring out the salient points and conclusions.

\section{EXISTING STATUS OF LEGISLATIVE FRAMEWORK}

In India the categorical distribution of sectors within the energy sector is by and large similar to many other countries. The classification of sectors is primarily done on the basis of energy resources. Therefore, a general classification of India's energy legislation can also be done on the basis of energy resources: (a) coal industry laws, (b) oil \& natural gas laws,(c) power sector laws,(d) atomic energy laws, (e) new \& renewable energy laws, and (f)energy conservation laws.[4].

The constitution has mandated the powers to the ministries under special articles to discharge their functions and duties. The energy laws are formulated by different ministries working in the energy sector and ultimately passed by the parliament. There are rules and regulations apart from the laws which are formulated by the ministries in the central government. The legislation provides guiding framework whereas rules and regulation are the logical extension of laws that give the executives further clarity to exercise laws in a better way. Additionally, there are some special legislative provisions to deal with specific issues that might arise from time to time.

There are some common policies pertaining to all energy sectors. These policies are broader in scope and cover a wide range of issues. Some such policies are - National Electricity Policy (2005), Rural Electrification Policy (2006), National Tariff Policy (2006), Integrated Energy Policy (IEP) (2006) and New Hydro Policy (2008), etc. Some sector specific policies are also formulated by the ministries and further substantiated by the prevailing laws and regulations. These are more detailed in nature and set the working procedure with more clarity. Some administrative regulations such as documents, statements and directives are issued by concerned central ministries as and when required and are to be followed by all the administrative functionaries and organizations. State and Local regulations are legal documents formulated by the state ministries, municipal bodies at local level and their Standing Committees. In Indian legal system, many laws and regulations have energy-related provisions; for example, environment and forest related laws. Energy standards are an integral part of the energy legal system as well. These could be classified as national, professional, local, compulsory and recommended standards. These are meant to bring in efficiencies at use level.

In the Indian energy sector, there have been number of energy laws, policies governing specific sector, state and local level energy regulations, administrative regulations and energy standards. Several international treaties have also been ratified. The energy laws are meant for developing a robust and sustainable energy supply and service system so that energy access to all can be made available at reasonable cost. It should enable the use and administration of energy, measures for increase in energy efficiency, creating a social and environmental friendly energy network, and promoting the development of sustainable society. As availability of energy is a right to common and rich alike, the poor section of society cannot be deprived of. Hence, economics of energy supply is required to be regulated in such a way that access to all is ensured without harming business interest of producers. Some important provisions of a few Acts are discussed in the following sections.

\subsection{Electricity Act, 2003}

Electricity Act, 2003 has proved to be a single most important legislative document which covers the entire electricity sector and has replaced the then existing legislations. A number of rules, regulations and policies have also been devised from the Act, which undoubtedly set the tone for future developments in power sector with the pace of economic improvement patching international standards. The success of the reform and 
restructuring processes depends upon various intangible bottlenecks that need to be evaluated quantitatively. All the measures under this act that have been taken in view of the holistic development of the sector can only lead to meaningful conclusions if integrated coordination is established among the various verticals and parallels of the government and associated stakeholders [3][6].

The key features of EA 2003 are as follows:

- Generation is free from licensing

- Constitution of Central Electricity Regulatory Commission and State Electricity Regulatory Commission

- Protecting the consumers interest and supplying electricity to all areas

- Open access to transmission network for all the participants

- Metering is mandatory

- Rationalization of tariff and lowering the cross-subsidization levels

- Recognition of Power trading as a distinct activity with ceilings on trading margin

- Consolidating the laws relating to generation, transmission, distribution, trading and use of electricity Setting up of Appellate Tribunal

- Multiple licensing in distribution

- Rural electrification

- Opportunities for investors

\subsection{Integrated Energy Policy (IEP), 2006}

India's energy sector has been witnessing various challenges on the account of energy shortages, lack of commercial practices, lack of harmonious coordination among the different stakeholders and many more related aspects. This has emphasized the need to integrate the sub-sectors of energy in view of holistic development of sector right from resource development to the final consumption in a sustainable manner. as follows:

The main areas of action in IEP, 2006 for which detailed policy recommendations have been made, are

- Augmenting energy resources and supply.

- Provide appropriate fiscal policies to take care of externalities; independent regulations to address anti-competitive market behavior

- Tax and regulatory structures should provide a level playing field for all sectors and all players

- Taxes should be neutral except in cases specifically intended to counter externalities such as environmental costs

- Transparent and targeted subsidies

- Promoting energy efficiency by enforcing standards effectively

- Promote competitive energy markets and leverage investment in the energy sector. Remove entry barriers to new players and imports

- Correct pricing of energy, in order to send the right signals to producers and consumers

- Incentives for renewable energy production to be linked to output and not just capacity addition

- Promoting coal imports.

- Accelerating power sector reforms

The broad vision behind the IEP, 2006 is to reliably meet the demand for energy services of all sectors including the lifeline energy needs of vulnerable households, in all parts of the country, with safe and convenient energy at lowest possible cost in a technically efficient, economically viable and environmentally sustainable manner [2]. The broad policy framework and the development thrusts suggested here need to be made more specific in certain areas [1].

\subsection{Provisions for Renewable Energy}

In the time of energy shortages and depleted fuels, new and renewable sources of energy supply deserve more attention. Environmental concerns have made the renewable energy even more crucial in the present context. Recent policy level developments promise to have significant contribution from the renewable sources of energy but this is to be viewed in the context of socio-economic dimensions and implementation realities [7].

The Electricity Act 2003 has outlined several enabling provisions to accelerate the development of renewable energy based generation such as promoting cogeneration and generation of electricity from renewable sources of energy. The Regulatory Commissions specify the obligations of various entities to procure a specific percentage of renewable energy out of the total consumption of electricity in the area of the distribution licensee. National Electricity Policy, 2005 and The IEP, 2006 also provide that progressively the share of 
electricity from non-conventional sources would need to be increased as prescribed by State Electricity Regulatory Commissions.

The increasing international recognition for India's renewable capacity enhancement and interest shown by foreign investors for building energy infrastructure with a special thrust on green energy has been seen recently. Bilateral/multilateral cooperation frameworks to promote renewable energy development have also been established.

\subsection{Nuclear Energy}

The Department of Atomic Energy since its inception has been able to establish a network of institutions engaged in R\&D as well as industrial activities and acquire expertise in all aspects of the nuclear fuel cycle. India has a flourishing and largely indigenous nuclear power program and expects to have 20,000 MW nuclear capacities on line by 2020 and 63,000 MW by 2032. It aims to supply $25 \%$ of electricity from nuclear power by 2050. The Indian Atomic Energy Commission (AEC) is the main policy body. The Nuclear Power Corporation of India Ltd (NPCIL) is responsible for design, construction, commissioning and operation of thermal nuclear power plants. However, the recent calamities seen in Fukushima (Japan) have hindered the progress and protest by environmental activist has become the cause of concern. The government is still continuing with its ambitious plan albeit with higher standards for safety and protection [9]. in Table-1.

A summary of the various legislations and policies as applicable to different energy sectors is presented

Table-1: Legislations and Policies Applicable to Energy Sectors

\begin{tabular}{|c|c|c|}
\hline Sector & Legislations (Acts/Laws) & Policies \\
\hline Electricity & $\begin{array}{ll}\text { - } & \text { Indian Electricity Act, } 1910 \\
\text { - } & \text { Electricity Supply Act, } 1948 \\
\text { - } & \text { Electricity Regulatory Commissions } \\
& \text { Act, } 1998 \\
\text { - } & \text { Electricity Act, } 2003 \\
\text { - } & \text { Electricity Amendment Act, } 2007 \\
\text { - } & \text { Energy Conservation Act, } 2001\end{array}$ & $\begin{array}{l}\text { - } \text { Mega power project policy } \\
\text { - } \text { Coal linkage policy } \\
\text { - National Electricity Policy, } 2005 \\
\text { - } \text { Rural Electrification Policy, } \\
2006 \\
\text { - National Electricity policy, } 2006 \\
\text { - National Tariff policy, } 2006 \\
\text { - Integrated Energy Policy, } 2006 \\
\text { - New Hydro policy, } 2008\end{array}$ \\
\hline Coal & $\begin{array}{ll}\text { - } & \text { Mines and Minerals (Development and } \\
& \text { Regulation) Act, } 1957 \\
\text { - } & \text { Mineral Concession Rules, } 1960 \\
\text { - } & \text { Coal Mine Regulation, } 1957 \\
\text { - } & \text { Coal Bearing Areas Acquisition \& } \\
& \text { Development Act, } 1957 \\
\text { - } & \text { Coal Mines (Nationalization) Act, } 1973 \\
\text { - } & \text { Coal Mines (Nationalization) Act, } 2000 \\
\text { - } & \text { Colliery Control Order, 1945 } \\
\text { - } & \text { Colliery Control Order, } 2000\end{array}$ & $\begin{array}{l}\text { - New coal Distribution Policy } \\
\text { - Import Policy } \\
\text { - Pricing Policy } \\
\text { - E-Auction Policy } \\
\text { - Exploration Licensing Policy }\end{array}$ \\
\hline Oil \& Natural Gas & $\begin{array}{l}\text { - } \text { The petroleum Act, } 1934 \\
\text { - } \text { The oilfield Act, } 1948 \\
\text { - } \quad \text { The petroleum pipelines Act, } 1962 \\
\text { - } \quad \text { The Oil Industry Act, } 1974 \\
\text { - } \text { Petroleum Rules, } 1976 \\
\text { - } \quad \text { P \& NG Rules, } 1959 \\
\text { - } \text { P \& NG Rules, } 2002 \\
\text { - P \& NG Rules, } 2009 \\
\text { - Petroleum \& Natural Gas Regulatory } \\
\text { Board Act, } 2006 \\
\text { - Safety in Offshore Operation Rules, } \\
\text { 2008 }\end{array}$ & $\begin{array}{l}\text { - Foreign Direct Investment } \\
\text { - Bio-Fuel Policy } \\
\text { - Policy on Disinvestment } \\
\text { - Gas Utilization Policy } \\
\text { - New Exploration Licensing } \\
\text { Policy (NELP) }\end{array}$ \\
\hline Atomic Energy & $\begin{array}{l}\text { - Atomic Energy (Control of Food } \\
\text { Irradiation) Rules, 1996 } \\
\text { - Atomic Energy (Radiation Protection) } \\
\text { Rules, 2004 }\end{array}$ & \\
\hline
\end{tabular}




\section{- Atomic Energy Act 1962 amended}

1987

- $\quad$ The Atomic Energy Act, 1962

Source: $[5][6][7][8][9]$

\section{Existing Institutional Structure}

India's energy sector is at present governed by four ministries according to fuel resources namely Ministry of Coal, Ministry of Power, Ministry of Oil \& Natural Gas and Ministry of New \& Renewable Energy. In addition to these ministries, Department of Atomic energy for nuclear energy directly works under Government of India. These ministries are responsible for full-fledged development of the respective sectors. There are several other agencies under each ministry which work in unison with them. Every state has separate ministry that is directly dependent on the central government for financial assistance and broad guidelines. However, the state bodies can also legislate if required. There are some state level agencies which work in close association with state ministries to operate different parallel functions. Central Government has relegated most of the administrative powers to the state governments in order to have proper management and monitoring of the functional organizations. Multiplicity of functional agencies with ambiguous objectives has hampered the growth of the sector and led to confusion among stakeholders. Time has come to do the reality check with the infusion of internationally best practices.

It has already been mentioned that the central ministry of the relevant sector is the apex body which decides the policies and management related aspects for the sector. Though there are number of associated agencies which work in tandem to the government and help influence decisions on various issues. For example, ministry of oil \& natural gas takes care of the sector as a whole and subsequently transfers duties and responsibilities to the other functional agencies and state ministries. The process majorly involves three functions, first exploration in the upstream sector then refining and marketing in the downstream sector. Each function is performed by both public and private sector companies as provisioned in the related laws. Earlier the industry operated in a monotonous way with almost entire functions being carried out by the government companies with few exceptions in the private sector. But subsequent reforms in order to introduce competition in the sector have resulted in keen participation from the private sector.

Ministry of New and Renewable Energy (MNRE) is the nodal Ministry of Government of India at the National level for all matters relating to new and renewable energy such as solar, wind, biomass, small hydro, hydrogen, bio fuels, and geothermal, etc. The Ministry adopts a three-fold strategy for the development, promotion and use of renewable energy technologies across the country: a) providing budgetary support for research, development and demonstration of technologies; b) facilitating institutional finance through various financial institutions; and c) promoting private investment through fiscal incentives, tax holidays, depreciation allowance and remunerative returns for power fed into the grid.

There are number of programmes running across India for promoting awareness among the people, promoting use of alternate sources, promoting self-sufficiency in power generation by the use of local sources like biomass, solar, etc. instead of depending on grid supply. International cooperation activities on development and deployment of new and renewable energy technologies are actively being pursued on bilateral and multilateral platforms.

\subsection{Impediments to legislation}

\section{Broad Impediments To Success}

- India's energy sector has always been the centre of talk in almost all policy planning circles at national level but it continues to lack the basic energy sector laws that are needed to govern the whole lot of issues leading to national energy security planning. Secondly, there are numerous specific sub-sector laws and regulations but they also have narrow focus and lack the overall perspective of national interest. These laws mostly talk about the administration and not of the performance. Thirdly, the most important deficiency is the lack of regulations for the energy at use stage. Energy efficient services and products are provided to the public at subsidized rate to encourage the efficient products but rational use of the same cannot be expected to happen without some regulations being in place. Fourthly, only realistic and implementable regulations need to be made and performance of these regulations is to be measured quantitatively. Otherwise they will not serve the purpose.

- In India, ministries have been empowered to develop full-fledged programme right from policy formulation to implementation. However, in reality they transfer the implementation to the functional agencies and consider that they have discharged their duties. Due to this, the ministries sometimes indulge into making of rules which are specific to their sector and ignore other associated concerns like energy conservation and environmental deterioration. 
- In India the legislative practices are largely borrowed from the British constitution and continue to operate even after so many years of independence. Many of these may not be suitable to Indian context and sometimes lead to dwindling performances which otherwise could have been better if the legislation were made with domestic know-how.

- There are number of laws, regulations and policies which work across the length and breadth of the sector. But many times such laws lack clarity and the purpose is lost. They should be spelt out clearly and deserves explicit mention. Responsibilities of implementing agencies should be clearly articulated and proper guidelines to measure performance are highly required.

- Some energy laws have become obsolete and are not fit in the present competitive global environment. They do not address certain issues rightfully. For example, the empirical formula for determining the quality of coal was based on then relevant parameters, which have become redundant in present conditions and need to be reformulated.

- Since most of the conventional energy resources are available in limited quantity and are certain to deplete, erratic and uncontrolled use of such resources should not be allowed. But reported history does not evince many such cases of legal actions where any uncontrolled use has been stopped. It needs to be looked upon with great caution.

- Often laws are very generic in nature and need further supportive policy documents and regulations for implementation. State and local level bodies need to be strengthened to be responsible for taking up decisions and drafting rules with regard to regional conditions which are specifically important in Indian context where there is a lot of geographical and cultural diversity.

- Very often the regulations are found silent on the critical issues and leave enough scope for misinterpretation and loopholes.

- The mechanism like single-window-clearances is required that speed up the process of clearances and approvals, and minimize the regulatory requirements. As these are often the stumbling blocks in turning out the projects in India. There have been numerous instances reported in India where projects are delayed because multiple administrative agencies work in different capacities at different hierarchy. Also international investors do not find it convenient to deal with such complexities and resulting dissatisfaction leads to low investment.

- Coordination among various stakeholders is highly desirable for the successful execution of projects. People often tend to work with the selfish motives which are certainly not in the social interest of the sector as a whole [10][11].

\subsection{Impediments to institutions}

We have seen that in the case of legislation there is a lack of documents addressing the national energy security planning, the same is replicated when it comes to managing the energy portfolio with national objective in mind at institutional level. Again the multiplicity of regulating, administrative and functional agencies has only led to confusion because of ambiguous mandate given to them. Regulators need to be empowered with greater scope of work. It should be extended to resource conservation which has alarming concerns of rapid depletion [10][11].

There is a lack of uniform system in place which explicitly articulates the roles and responsibilities of each of the functionaries and a clear mechanism to check their performance. A systematic development plan needs to be chalked out, accepted and implemented without any hidden objectives. The body at centre like national energy commission is highly desirable in India because Indian economy is moving at rapid growth rate and stands ahead in emerging economies in the world. There are several independent bodies which work individually for the energy sector but do not have the national level development in focus. The coordinated development of the sector requires all the supportive agencies to work in tandem with the central ministries and fulfill the objective of safe, clean and sustainable operations, which is often found missing in the Indian context.

\section{Way Forward To Improvisations}

- Energy Sector Reforms and Truth: There have been rounds of reforms and restructuring with a view to ensure efficient practices across the value chain. It follows the international experiences and has resulted in some demonstrable gains. Almost every sub-sector has undergone legitimate shifting from one form to other. But have these reforms resulted in the desired output? Perhaps not. Therefore, objectives of reforms need to be reviewed and restated with more clarity. For example, privatization is considered to be the best way to fetch competition but some countries like Norway have efficient market without privatization.

- Need of Regulators and their Accountability: Only the power sector has the regulatory commission in centre and states as well. All other sectors are still waiting to have one for them. The principal theme is to infuse competitive efficiency in the energy sector since the sector is characterized by large economies of scale and 
has natural monopoly in some sub-sectors. Since, domain knowledge is important, a common regulator is not recommended for all energy sub-sectors. However, these regulators for each sub-sector should enable cohesion in working for betterment of the sector as a whole. The commission should be empowered to take suomoto decisions on the subordinate legislations made by different ministries or departments.

- Benchmarking of Standards: Responsibilities need to be explicitly mentioned for every stakeholder to ensure hassle free coordination. There should be properly written guiding procedure for every working arm of the ministry. Performance should be assessed with quantitative parameters that would help in making future strategy. Hence, improvement across the sectoral activities.

- Stop Politicizing the Public Issues: Political interventions in the development of the energy sector have been found to have critical impact. Many such movements led by political activists are often driven by political mileage than the public concerns. Of late, evidences for project closure, changing locations and protest for nuclear projects have been seen due to political rivalry. This has proved to be a barrier in the development of competitive environment and market based practices.

- Policies that are Implementable: It is commonly believed that policymakers are often not aware about the ground realities and do closed room working without actually accessing the practical conditions. Implementable solutions and policies are highly required to convert well written policies into well executed one.

- Smoothen the Process of Giving Clearances: Regulatory mechanism should facilitate and not delay the projects in many ways. There should be time-bound delivery against each activity, failure to which will have the penalty. This is expected to result speedy approvals and execution in the stipulated time.

- International Associations: It would be useful to understand the working efficiencies and procedures of international associations and how it can be suitably adopted to Indian conditions. These associations in many ways have quite an obvious impact like sharing of technological innovations, trading agreements and knowledge for the betterment of energy sector.

- Skilled Human Capital: In India, lack of technical training institutions have resulted in reduced working efficiencies. Manpower development is necessary to equip them with proper skills that are directly utilizable at workplace.

\section{Summing Up}

It has been highlighted in the earlier sections of this paper that despite many reforms, multiplicity of legislations and institutions in India's energy sector has resulted in hindered progress and the outcomes are not satisfactory. The current structure in India is the result of reforms and restructuring processes that have been initiated from time to time. These reforms have largely focused on the specific sectors and have not been able to keep pace with the required development of integral approach for the energy sector a whole. It can be said that there are severe deficiencies that demands immediate attention and action.

Firstly, it is high time that building up of strong legislative provisions is started that cover all the subsectors of energy including technical, commercial, operational, administrative, conservation, environmental, security, legal and market related aspects with overall national development agenda in focus. Energy laws are required to be stated with more clarity and focus leaving no place for ambiguities in comprehension. The scope of every law and regulation needs to be clearly spelt out so that expected and desirable results can be seen. The laws should also incorporate the provisions for compensation and legal actions.

The second equally important aspect is to have the robust institutional framework with each functionary having clearly articulated mandate and check posts for performance. This should not be a onetime exercise as the periodical reviews, monitoring, feedback and problem-solving is a key to success.

\section{REFERENCES}

[1]. www.pib.nic.in/newsite/

[2]. Planning Commission, 2006, "Integrated energy policy: report of the Expert Committee." Available from: http://planningcommission.nic.in/reports/genrep/rep_intengy.pdf;

[3]. "Indian Power Sector: Holistic Capacity Building", September 11-13, 2008, International Conference on Power Sector organized by FICCI

[4]. Xiaojiang Yu, An overview of legislative and institutional approaches to China's energy development, Energy Policy, 38,2010, $2161-2167$

[5]. http://coal.gov.in/welcome.html

[6]. http://powermin.nic.in/

[7]. http://www.mnre.gov.in/

[8]. http://www.petroleum.nic.in/

[9]. http://www.dae.gov.in/index 1.html

[10]. India country report, From ideas to action: clean energy solutions, For asia to address climate change, USAID, June, 2007

[11]. Clean Energy: An Exporter's Guide to India, http://trade.gov, July, 2008 